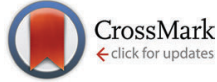

Cite this: Phys. Chem. Chem. Phys., $2014,16,23404$

\title{
Effect of torsional twist on 2nd order non-linear optical activity of anthracene and pyrene tricyanofuran derivatives $\dagger$
}

\author{
Miquel Planells, ${ }^{a}$ Maddalena Pizzotti, ${ }^{b}$ Gary S. Nichol, ${ }^{a}$ Francesca Tessore ${ }^{b}$ and \\ Neil Robertson*a
}

\begin{abstract}
Tricyanofuran (TCF) derivatives attached to both anthracene and pyrene moieties were synthesised and characterised by optical, electrochemical and computational techniques. Both compounds exhibited similar absorption profile as well as electrochemical behaviour, however the pyrene derivative showed 20-fold higher non-linear optical activity measured by the EFISH technique. This huge difference has been assigned to (i) a lower molar absorption and (ii) a higher torsion angle for the anthracene derivative, confirmed by both experimental $X$-ray diffraction and DFT calculations. Furthermore, we note that the $\mu \beta_{1.907}$ value of $-1700 \times 10^{-48}$ esu recorded for the pyrene derivative in $\mathrm{CHCl}_{3} /$ pyridine is remarkable for a NLO chromophore lacking a classical push-pull structure.
\end{abstract}

Received 6th August 2014,
Accepted 23rd September 2014

DOI: $10.1039 / \mathrm{c} 4 \mathrm{cp} 03509 \mathrm{~g}$

www.rsc.org/pccp

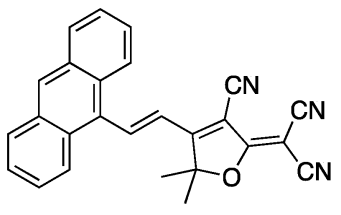

Anth_TCF<smiles>CC1(C)OC(=C(C#N)C#N)C(C#N)=C1/C=C/c1ccc2ccc3cccc4ccc1c2c34</smiles>

Pyr_TCF and electro-optical devices. ${ }^{1-4}$ In the last two decades a large research effort has been devoted to the definition of the main features that a molecule must possess in order to show a significant second-order NLO response, and up to now many examples of both organic ${ }^{5,6}$ and organometallic ${ }^{7,8}$ NLO chromophores have been reported in the literature, some of which display very remarkable responses. ${ }^{9}$

Their basic structure consists of an electron-donor (D) and an electron-acceptor (A) group interacting through a $\pi$-conjugated spacer, giving rise to a D- $\pi-\mathrm{A}$ dipolar push-pull architecture with significant intramolecular charge transfer (ICT) properties, so that a certain extent of charge separation in the ground state can be achieved.

According to Oudar's "two-level" model, ${ }^{10,11}$ the magnitude of the molecular second order response figure of merit $\beta$ (the so called second-order polarisability or first order hyperpolarisability)

\footnotetext{
${ }^{a}$ EastChem - School of Chemistry, Kings Buildings, University of Edinburgh, Edinburgh, EH9 3JJ, UK. E-mail: neil.robertson@ed.ac.uk

${ }^{b}$ Dipartimento di Chimica dell'Università degli Studi di Milano, Unità di Ricerca dell'INSTM, via C. Golgi 19, 20133 Milano, Italy

$\dagger$ Electronic supplementary information (ESI) available: ${ }^{1} \mathrm{H}$ and ${ }^{13} \mathrm{C}$ NMR spectra, FT-IR traces, cyclic voltammetry scans and extended TD-DFT orbital contribution. CCDC 933499 and 933500. For ESI and crystallographic data in CIF or other electronic format see DOI: 10.1039/c4cp03509g
}

Fig. 1 Chemical structures of TCF derivatives used in this study.

is related to the length of the $\pi$-delocalized bridge and to the strength of the donor and the acceptor substituents.

Among the latter, 2-dicyanomethylidene-3-cyano-4,5,5-trimethyl2,5-dihydrofuran (TCF) ${ }^{12}$ and its analogue $\mathrm{CF}_{3}-\mathrm{TCF}^{13}$ proved to be very efficient electron-withdrawing moieties. When linked to aromatic donors such as anilines ${ }^{14,15}$ or proaromatic 1,3-dithiole donors $^{16}$ they produced NLO-chromophores with very high $\beta$ values.

Here, we report the synthesis and characterisation of two TCF derivatives containing the polycyclic aromatic moieties anthracene and pyrene (Fig. 1). We discuss the absorption, electrochemical and non-linear optical behaviour of those molecules and correlate their properties with the structure obtained by both X-ray diffraction and computational methods.

\section{Experimental section}

\section{Synthetic procedure}

Materials. All reagents were purchased from either SigmaAldrich or Alfa-Aesar and were used as received without further 
purification unless otherwise stated. 2-Dicyanomethylidene-3cyano-4,5,5-trimethyl-2,5-dihydrofuran (TCF) was synthesized following the procedure described previously. ${ }^{17}$

Synthesis of (E)-2-(4-(2-(anthracen-9-yl)vinyl)-3-cyano-5,5dimethylfuran-2(5H)-ylidene)malononitrile (Anth_TCF). Anthacene9-carbaldehyde (206 mg, $1 \mathrm{mmol}$ ) and TCF (219 mg, $1.1 \mathrm{mmol}$ ) were placed in a Schlenk tube with $8 \mathrm{~mL}$ of ethanol. Triethylamine $(13 \mu \mathrm{L}, 0.1 \mathrm{mmol})$ was added, and the mixture was stirred under $\mathrm{N}_{2}$ overnight at reflux temperature. After cooling to room temp., a purple precipitate with metallic green reflections was collected by filtration and washed with cold ethanol $(20 \mathrm{~mL})$. Yield $250 \mathrm{mg}$ (64\%). m.p.: $250{ }^{\circ} \mathrm{C} .{ }^{1} \mathrm{H}$ NMR $(500 \mathrm{MHz}$, $\left.\mathrm{CDCl}_{3}\right) \delta_{\mathrm{H}}: 8.89(\mathrm{~d}, J=16.6,1 \mathrm{H}) ; 8.57(\mathrm{~s}, 1 \mathrm{H}) ; 8.18(\mathrm{~d}, J=8.8,2 \mathrm{H})$; $8.08(\mathrm{~d}, J=8.3,2 \mathrm{H}) ; 7.62(\mathrm{t}, J=7.7,2 \mathrm{H}) ; 7.56(\mathrm{t}, J=7.6,2 \mathrm{H}) ; 7.05$ $(\mathrm{d}, J=16.5,1 \mathrm{H}) ; 1.92(\mathrm{~s}, 6 \mathrm{H}) .{ }^{13} \mathrm{C}$ NMR $\left(125 \mathrm{MHz}, \mathrm{CDCl}_{3}\right) \delta_{\mathrm{c}}$ : $175.4 ; 173.3 ; 145.1 ; 131.7 ; 131.5 ; 130.1 ; 129.8 ; 128.2 ; 126.1$; $124.3 ; 123.3 ; 111.7 ; 110.8 ; 110.6 ; 100.1 ; 98.1 ; 58.7 ; 26.5$. MS EI $(\mathrm{m} / \mathrm{z}):[\mathrm{M}]^{+}$calcd for $\mathrm{C}_{26} \mathrm{H}_{17} \mathrm{~N}_{3} \mathrm{O}$ : 387.13716; found: 387.13662 . FT-IR $\left(\mathrm{cm}^{-1}\right)$ : 2224, 1560, 1546, 1524, 1377, 1337, 1306, 1240, 1106, 1084, 902, 728, 662. Anal. calcd for $\mathrm{C}_{22} \mathrm{H}_{15} \mathrm{~N}_{3} \mathrm{O}: \mathrm{C}, 80.60 ; \mathrm{H}$, 4.42; N, 10.85; found: C, 80.44; H, 4.35; N, 10.76 .

Synthesis of (E)-2-(3-cyano-5,5-dimethyl-4-(2-(pyren-1-yl)vinyl)furan-2(5H)-ylidene)malononitrile (Pyr_TCF). Pyrene-1-carbaldehyde (691 $\mathrm{mg}, 3 \mathrm{mmol}$ ) and TCF (600 $\mathrm{mg}, 3 \mathrm{mmol}$ ) were placed in a Schlenk tube with $60 \mathrm{~mL}$ of ethanol. Triethylamine $(42 \mu \mathrm{L}$, $0.3 \mathrm{mmol}$ ) was added, and the mixture was stirred under $\mathrm{N}_{2}$ overnight at reflux temperature. After cooling to room temp., a purple precipitate with metallic green reflections was collected by filtration and washed with cold ethanol $(20 \mathrm{~mL})$ and $\mathrm{CHCl}_{3}$ $(20 \mathrm{~mL})$. Yield $699 \mathrm{mg}(54 \%)$. m.p.: $330{ }^{\circ} \mathrm{C}$. This molecule is not soluble enough for NMR measurements. MS EI $(\mathrm{m} / \mathrm{z}):[\mathbf{M}]^{+}$calcd for $\mathrm{C}_{28} \mathrm{H}_{17} \mathrm{~N}_{3} \mathrm{O}$ : 411.13661; found: 411.136346. FT-IR $\left(\mathrm{cm}^{-1}\right)$ : 2223, 1548, 1521, 1498, 1471, 1397, 1373, 1362, 1303, 1280, $1253,1214,1191,1093,837,650$. Anal. calcd for $\mathrm{C}_{22} \mathrm{H}_{15} \mathrm{~N}_{3} \mathrm{O}: \mathrm{C}$, 81.73; H, 4.16; N, 10.21; found: C, 81.84; H, 4.08; N, 10.17 .

\section{Methods}

Chemical characterisation. ${ }^{1} \mathrm{H}$ and ${ }^{13} \mathrm{C}$ NMR spectra were recorded on Bruker Advance 500 spectrometer $\left(500 \mathrm{MHz}\right.$ for ${ }^{1} \mathrm{H}$ and $125 \mathrm{MHz}$ for ${ }^{13} \mathrm{C}$ ). The deuterated solvents are indicated; chemical shifts, $\delta$, are given in ppm, referenced to the solvent residual signal $\left({ }^{1} \mathrm{H},{ }^{13} \mathrm{C}\right)$. Coupling constants $(J)$ are given in $\mathrm{Hz}$. MS were recorded on ThermoElectron MAT 900 using electron impact (EI) ionization technique. FT-IR spectra were recorded using a Perkin-Elmer Spectrum 65 FT-IR spectrometer with solid-state samples. Elemental analyses were carried out by Stephen Boyer at London Metropolitan University using a Carlo Erba CE1108 Elemental Analyser.

Electrochemical characterisation. All cyclic voltammetry measurements were carried out in freshly distilled $\mathrm{CH}_{2} \mathrm{Cl}_{2}$ using $0.1 \mathrm{M}[\mathrm{TBA}]\left[\mathrm{PF}_{6}\right]$ electrolyte in a three-electrode system, with each solution being purged with $\mathrm{N}_{2}$ prior to measurement. The working electrode was a Pt disk. The reference electrode was $\mathrm{Ag} / \mathrm{AgCl}$ and the counter electrode was a $\mathrm{Pt}$ rod. All measurements were made at r.t. using an $\mu$ AUTOLAB Type III potentiostat, driven by the electrochemical software GPES.
Cyclic voltammetry (CV) measurements used scan rates of 25, $50,100,200$ and $500 \mathrm{mV} \mathrm{s}^{-1}$, and differential pulse voltammetry (DPV) was carried out at a step potential of $10 \mathrm{mV}$, modulation amplitude of $100 \mathrm{mV}$, modulation time of $0.05 \mathrm{~s}$ and an interval time of $0.5 \mathrm{~s}$, giving a scan rate of $20 \mathrm{mV} \mathrm{s}^{-1}$. Ferrocene was used as internal standard in each measurement.

Optical characterisation. Solution UV-Visible absorption spectra were recorded using Jasco V-670 UV/Vis/NIR spectrophotometer in various solvents controlled using the SpectraManager software. All samples were measured in a $1 \mathrm{~cm}$ quartz cuvette cell at room temp.

Computational details. The molecular structures were optimized first in vacuum without any symmetry constrains, followed by the addition of solvation contribution via a conductorlike polarizable continuum model (C-PCM) ${ }^{18}$ The presence of local minimum was confirmed by the absence of imaginary frequencies. All calculations were carried out using the Gaussian 09 programme $^{19}$ with the Becke three parameter hybrid exchange, Lee-Yang-Parr correlation functional (B3LYP) level of theory. All atoms were described by the $6-31 G(d)$ basis set. All structures were input and processed through Avogadro software package. $^{20}$ The lowest 10 singlet excited states where calculated with the time-dependent DFT (TD-DFT) formalism, as implemented in Gaussian $09^{21,22}$ and processed with GaussSum software package. ${ }^{23}$ In order to evaluate the differences between the dipole moments of the excited state and that of the ground state $\left(\Delta \mu_{\mathrm{ge}}\right)$, we simulated the Stark effect by TD-DFT methods, taking into account the difference in the lowest transition energies calculated with and without an external electric field of \pm 0.0005 a.u. of strength. ${ }^{24}$

Crystallographic details. Crystallographic data were collected on an Agilent Technologies SuperNova with $\mathrm{Cu} \mathrm{K} \alpha(\lambda=1.54178 \AA$ A $)$ radiation at $120 \mathrm{~K}$. Single crystals suitable for X-ray diffraction (XRD) were prepared by slow evaporation of $\mathrm{CHCl}_{3}$ for Anth_TCF and $\mathrm{CH}_{2} \mathrm{Cl}_{2}$ for Pyr_TCF. A summary of data collection and structure refinement is reported in Table 1. Programs used were: data collection and reduction, CrysAlisPro; ${ }^{25}$ structure solution, Sir92; ${ }^{26}$ structure refinement, SHELXTL. ${ }^{27}$ The crystal structures were deposited at CCDC with deposition number 933499 and 933500 for Anth_TCF and Pyr_TCF, respectively.

NLO measurements. The second order nonlinear optical properties of Anth_TCF and Pyr_TCF were assessed at a molecular level by means of the Electric Field Induced Second Harmonic generation (EFISH) technique, ${ }^{28-30}$ using a prototype apparatus made by SOPRA (France), and working with a $1.907 \mu \mathrm{m}$ incident wavelength. For each chromophore, experiments were performed on freshly prepared solutions in $\mathrm{CHCl}_{3}$ at $5 \times 10^{-4} \mathrm{M}$ concentration. On Pyr_TCF a measurement in $\mathrm{CHCl}_{3}$ with addition of pyridine $(1.6 \%$ in volume with respect to $\mathrm{CHCl}_{3}$ and 200 molar ratio with respect to Pyr_TCF) was also performed. The addition of pyridine allowed us to work at higher concentration than in neat $\mathrm{CHCl}_{3}\left(10^{-3} \mathrm{M}\right)$.

The $1.907 \mu \mathrm{m}$ laser incident wavelength was chosen because its second harmonic (at $953 \mathrm{~nm}$ ) is far enough from the absorption bands of both Anth_TCF and Pyr_TCF in $\mathbf{C H C l}_{3}$ $\left(\lambda_{\max }=540\right.$ and $533 \mathrm{~nm}$, respectively, see Table 3 and Fig. 4), 
Table 1 X-ray crystallographic data for Anth_TCF and Pyr_TCF

\begin{tabular}{|c|c|c|}
\hline & Anth_TCF & Pyr_TCF \\
\hline Emp. form & $\mathrm{C}_{26} \mathrm{H}_{17} \mathrm{~N}_{3} \mathrm{O}$ & $\mathrm{C}_{28} \mathrm{H}_{19} \mathrm{~N}_{3} \mathrm{O} \cdot \mathrm{CH}_{2} \mathrm{Cl}_{2}$ \\
\hline$M_{\mathrm{w}}$ & 387.43 & 498.39 \\
\hline Colour, habit & Black, rhombus & Purple, block \\
\hline Cryst. size/mm & $0.08 \times 0.04 \times 0.01$ & $0.239 \times 0.207 \times 0.016$ \\
\hline Cryst. syst. & Monoclinic & Monoclinic \\
\hline Space group & $P 2_{1} / c$ & $P 2_{1} / c$ \\
\hline$a / \AA$ & $10.3685(7)$ & $22.424(4)$ \\
\hline$b / \AA ̊ ̊$ & $26.7860(14)$ & $15.2492(19)$ \\
\hline$c / \AA ̊ ̊$ & $7.3961(6)$ & $6.8252(13)$ \\
\hline$\beta /^{\circ}$ & $104.892(8)$ & 98.75 \\
\hline$V / \AA^{3}$ & $1985.1(2)$ & $2306.7(7)$ \\
\hline$Z$ & 4 & 4 \\
\hline$\rho / \mathrm{g} \mathrm{cm}^{-3}$ & 1.296 & 1.435 \\
\hline$\mu / \mathrm{mm}^{-1}$ & 0.639 & 2.761 \\
\hline$\theta$ range $/^{\circ}$ & 3.3 to $67.1^{\circ}$ & 3.5 to $53.3^{\circ}$ \\
\hline No. of rfln, unique & 14424,3539 & 20014,2555 \\
\hline Compl. to $\theta_{\max } / \%$ & 100 & 61.2 \\
\hline$R_{1}$ & 0.0505 & 0.2111 \\
\hline $\mathrm{w} R_{2}$ & 0.1075 & 0.4705 \\
\hline GooF & 1.040 & 2.793 \\
\hline
\end{tabular}

to avoid any enhancement of the second order non-linear optical response due to resonance. The incident beam was obtained by Raman shifting the $1.064 \mu \mathrm{m}$ emission of a Qswitched Nd:YAG laser in a high pressure hydrogen cell (60 bar). A liquid cell with thick windows in the wedge configuration was used to obtain the Maker fringe pattern (harmonic intensity variation as a function of liquid cell translation). In the EFISH experiments the incident beam was synchronized with a DC field applied to the solution, with 60 and 20 ns pulse duration respectively in order to break its centrosymmetry. From the concentration dependence of the harmonic signal with respect to that of the pure solvent, the NLO responses were determined (assumed to be real because the imaginary part was neglected) from the experimental value $\gamma_{\mathrm{EFISH}}$, through eqn (1):

$$
\gamma_{\mathrm{EFISH}}=\frac{\mu \beta_{\lambda}(-2 \omega ; \omega, \omega)}{5 k T}+\gamma(-2 \omega ; \omega, \omega, 0)
$$

where $\gamma_{\text {EFISH }}$ is the sum of a cubic electronic contribution $\gamma(-2 \omega ; \omega, \omega, 0)$ and of a quadratic orientational contribution $\mu \beta_{\lambda}(-2 \omega ; \omega, \omega) / 5 k T, \mu$ being the ground state dipole moment, and $\beta_{\lambda}$ the projection along the dipole moment direction of the vectorial component $\beta_{\text {vec }}$ of the tensorial quadratic hyperpolarisability working with the incident wavelength $\lambda$. For molecules with one dominant ICT transition along the donor-acceptor axis, the third order electronic contribution to $\gamma_{\mathrm{EFISH}}$ can safely be neglected. ${ }^{30}$

The $\mu \beta_{\lambda}$ reported in Table 4 are the mean values of twelve successive measurements performed on the same sample. The sign of $\mu \beta_{\lambda}$ is determined by comparison with the reference solvent.

All experimental EFISH $\beta_{\lambda}$ values are defined according to the "phenomenological" convention. ${ }^{31}$ EFISH experiments were carried out in the Chemistry Department of the University of Milano (Italy).

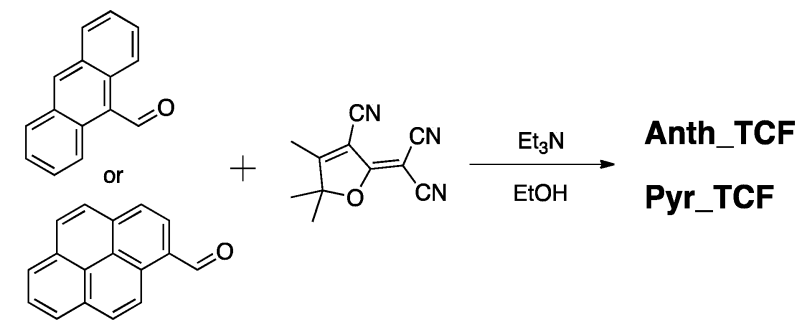

Scheme 1 Synthetic procedure for anthracene and pyrene TCF derivatives.

\section{Results and discussion}

\section{Synthesis}

TCF derivatives have been obtained by reacting the corresponding polyaromatic hydrocarbon aldehyde with the TCF moiety in the presence of catalytic base in ethanol as shown in Scheme $1 .^{32}$ The solubility of Pyr_TCF was limited and NMR could not be obtained. However, proper identification was achieved by high-resolution mass spectrometry, FT-IR showing the nitrile stretch vibration at $2230 \mathrm{~cm}^{-1}$ (Fig. S3, ESI $\dagger$ ) and X-ray diffraction (Fig. 2).

\section{X-ray structures}

Molecular structures of compounds Anth_TCF and Pyr_TCF are shown in Fig. 2. Obtaining satisfactory single crystal X-ray diffraction data for Pyr_TCF was difficult. The compound was recrystallised by different methods on several occasions with each attempt consistently yielding thin plate crystals. The observed diffraction pattern each time was badly streaked, a likely result of plate stacking faults, and in most cases was unindexable. Eventually a set of crystals were obtained by slow evaporation of a $\mathrm{CH}_{2} \mathrm{Cl}_{2}$ solution; a crystal was found from which the measured diffraction was sufficient to allow for a unit cell determination and subsequently a data collection.

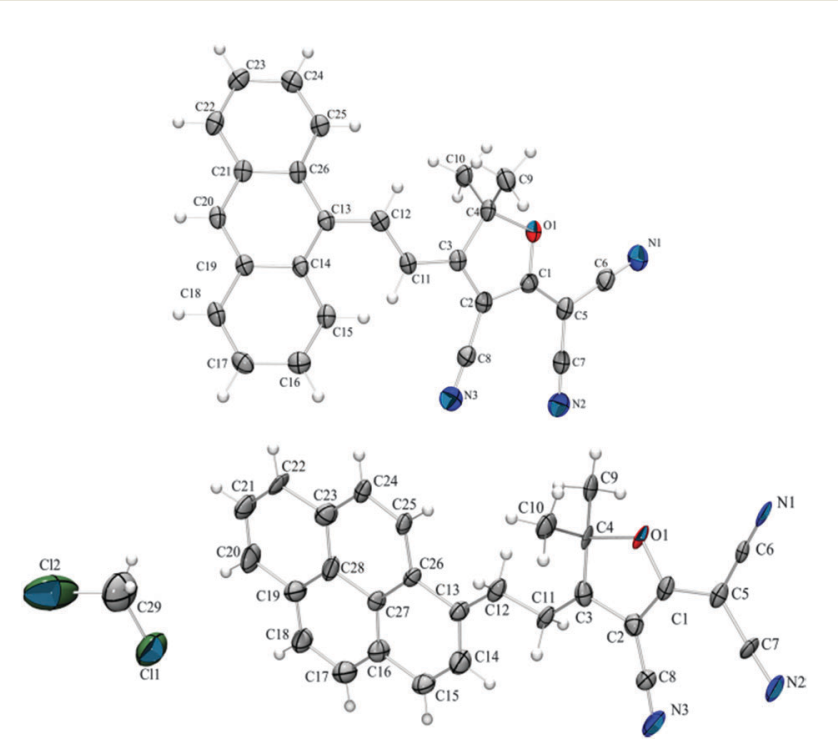

Fig. 2 ORTEP drawings of Anth_TCF (top) and Pyr_TCF (bottom) with thermal ellipsoids drawn at the $50 \%$ probability level. 


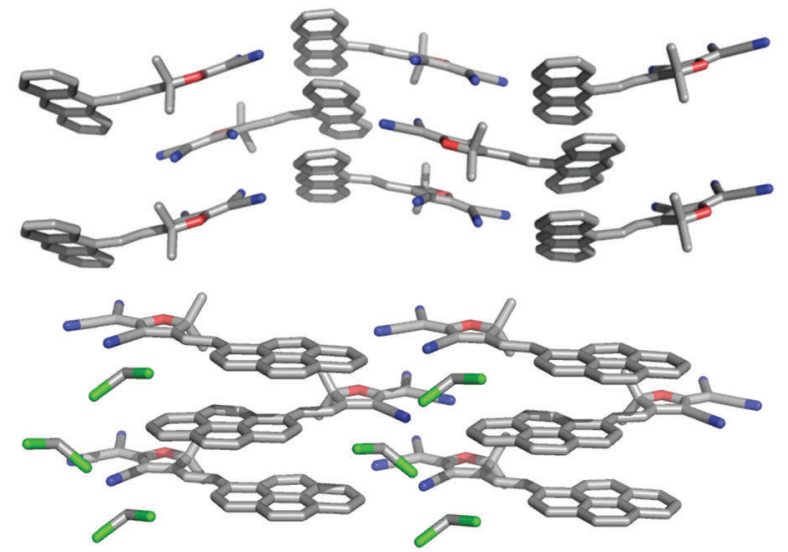

Fig. 3 Crystal packing of Anth_TCF (top) and Pyr_TCF (bottom). Hydrogens have been omitted for clarity.

The measured data set was very weak thus the data set was cut at $1.3 \AA$ resolution. Although the structure solved easily by direct methods the poorly crystalline nature of the compound resulted in a refinement model with high residuals, $R_{1}=$ $23.95 \%$ and $\mathrm{w} R_{2}=48.19 \%$. The data quality is sufficient to allow for unambiguous identification of the covalently bonded species in the asymmetric unit and the structure is reasonable enough to fit least squares planes through the pyrene atoms and determine the distance between them. The poor data resolution reduces the precision of the derived bond distances and angles, but does not affect the overall covalently-bonded picture of the molecule, the stacking pattern or the torsion angle. We note that the inclusion of $\mathrm{CH}_{2} \mathrm{Cl}_{2}$ in the lattice is consistent with the inability to obtain reasonable-quality crystals from other solvents.

The crystal packing of Anth_TCF and Pyr_TCF is depicted in Fig. 3. The packing did not follow a head-to-tail motif, as expected for non-symmetrical molecules. ${ }^{33,34}$ This is probably due to the steric hindrance corresponding to the methyl units on the TCF moiety, as observed in a related naphthalene derivative previously. ${ }^{17}$ For our anthracene and pyrene derivatives, polycyclic aromatic units overlapped each other giving an intermolecular distance of 3.47 and $3.41 \AA$ for Anth_TCF and Pyr_TCF, respectively. Those short intramolecular distances denote a strong $\pi-\pi$ interaction between the polycyclic aromatic moieties.

Despite the similar packing pattern and intermolecular distances, there is a major difference in the molecular structures related to the torsion angle between the polycyclic aromatic moiety and TCF unit. For Anth_TCF, there is a remarkable twist of approximately 33.8 degrees between anthracene and TCF units. This is mainly due to the steric hindrance of 9-substituted anthracene derivatives. On the other hand, Pyr_TCF shows a minor twist angle smaller than 1 degree. This effect is also reflected in the DFT calculations and has a potential effect on the non-linear optical properties, as discussed below.

\section{Electrochemical properties}

Cyclic voltammetry (CV) experiments were performed in $\mathrm{CH}_{2} \mathrm{Cl}_{2}$ solution, showing an irreversible behaviour for the reduction

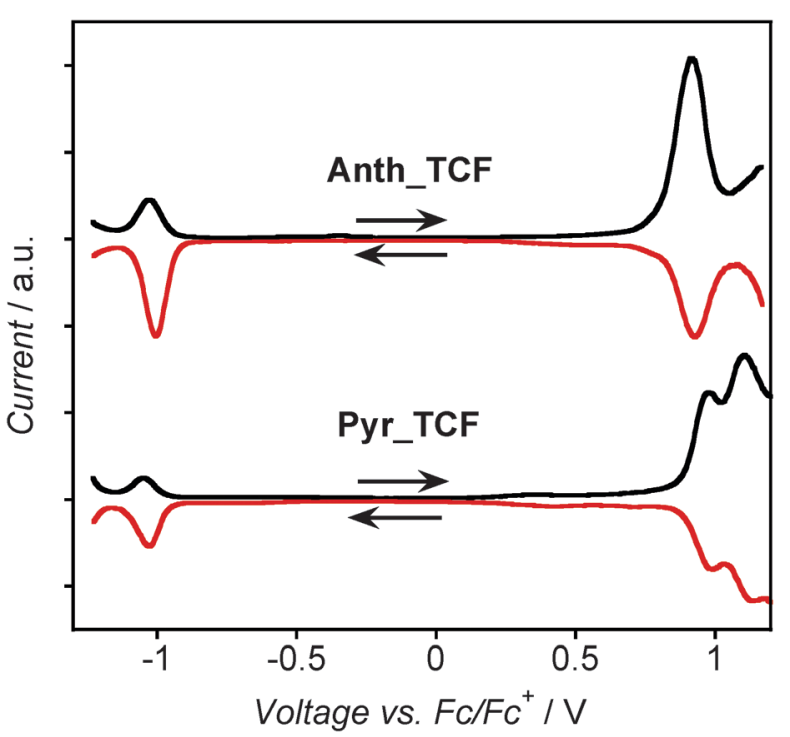

Fig. 4 Differential pulse voltammetry of Anth_TCF (top) and Pyr_TCF (bottom) recorded in $\mathrm{CH}_{2} \mathrm{Cl}_{2}$ solution containing $0.1 \mathrm{M}$ [TBA] $\left[\mathrm{PF}_{6}\right]$ and referenced to ferrocene. Arrows indicate the direction of scan.

process (Fig. S4, ESI $\dagger$ ). The reduction processes is assigned to take place at the TCF moiety, and as expected this process occurred at the same potential for the two molecules. On the other hand, oxidation cannot be reliably measured in the CV experiments because that process occurs on the edge of the solvent electrochemical window. Therefore, differential pulse voltammetry (DPV) was used in order to elucidate the oxidation processes (Fig. 4). Results are shown in Table 2. Several points should be highlighted: (i) the irreversibility of the reduction processes can be confirmed by DPV due to both peak shift and intensity after scanning forward and backwards; (ii) a single oxidation process can be observed for Anth_TCF whereas two oxidation processes occurred for Pyr_TCF; (iii) due to the lack of CV data for oxidative processes, we cannot elucidate the reversibility of this process; and (iv) the electrochemical gap is very similar for both compounds, which is in a good agreement with optical and computational results (see discussion below).

\section{Optical properties and EFISH measurements}

UV-Visible spectra have been recorded in a variety of solvents. The intense absorption in the visible region can be assigned to an ICT from the $\pi$-conjugated system to the electron acceptor unit, as previously reported for the analogous naphthyl derivative $^{17}$ and hereafter supported by the theoretical calculations.

Table 2 Electrochemical data measured in $\mathrm{CH}_{2} \mathrm{Cl}_{2}, 0.1 \mathrm{M}$ [TBA] $\left[\mathrm{PF}_{6}\right]$, and referenced to ferrocene

\begin{tabular}{lllll}
\hline & $\begin{array}{l}E_{\mathrm{a}}{ }^{a}(\mathrm{~V}) \\
-1 \rightarrow 0\end{array}$ & $\begin{array}{l}E_{\mathrm{c}}^{1 a}(\mathrm{~V}) \\
0 \rightarrow+1\end{array}$ & $\begin{array}{l}E_{\mathrm{c}}^{2 a}(\mathrm{~V}) \\
+1 \rightarrow+2\end{array}$ & $E_{\text {gap }}{ }^{b}(\mathrm{~V})$ \\
\hline Naph_TCF & -1.01 & +0.92 & $\mathrm{n} / \mathrm{o}^{c}$ & 1.93 \\
Pyr_TCF & -1.03 & +0.98 & +1.11 & 2.01
\end{tabular}

${ }^{a}$ Irreversible electrochemical wave. ${ }^{b}$ Electrochemical band gap: $E_{\text {gap }}=E_{\mathrm{c}}^{1}-E_{\mathrm{a}} \cdot{ }^{c}$ Non observed. 

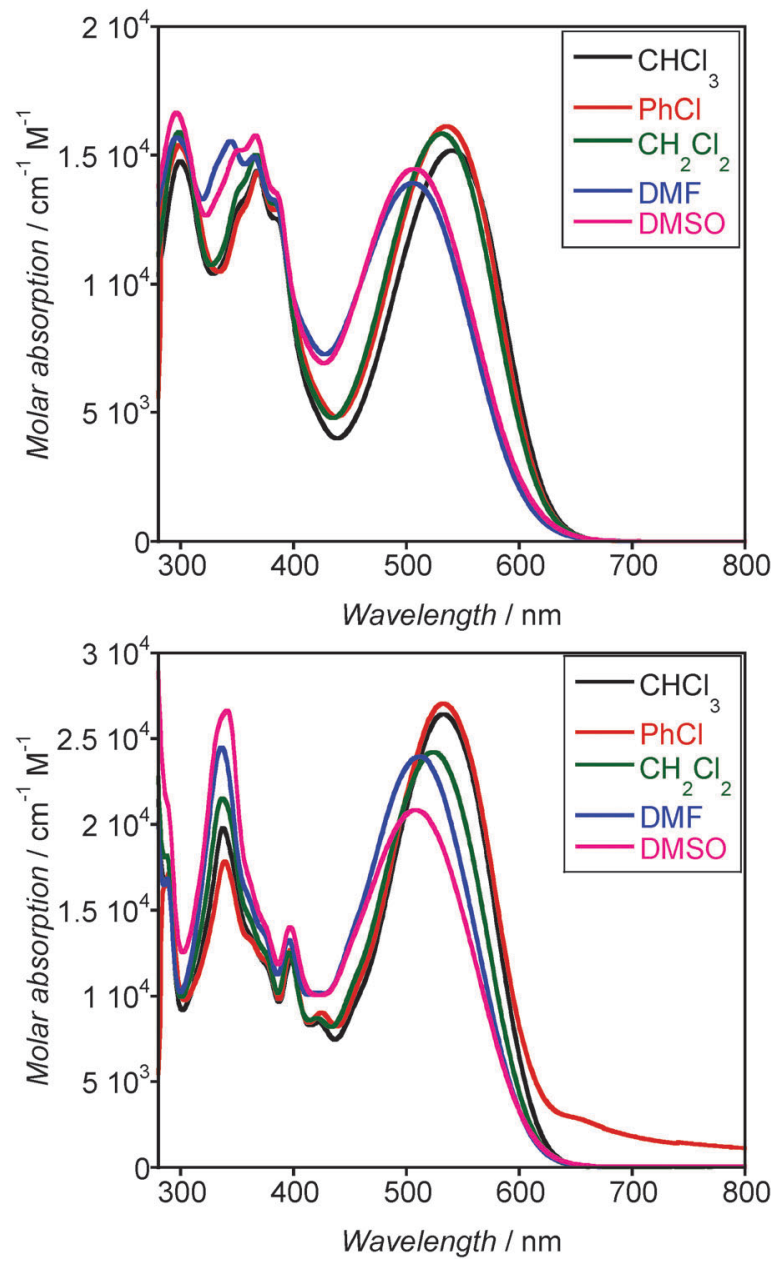

Fig. 5 UV-Visible absorption spectra of Anth_TCF (top) and Pyr_TCF (bottom) in various solvents acquired at $5 \times 10^{-5} \mathrm{M}$.

For both compounds, remarkable solvatochromic behaviour is evident (Fig. 5). This is expected for such donor-acceptor molecules and indicates a significant difference in charge distribution between the ground and excited states. ${ }^{35}$ The hypsochromic shift of the absorption maximum $\left(\lambda_{\max }\right)$ with increasing solvent polarity (i.e. negative solvatochromism) implies that the dipole moment of the excited state is lower than that of the ground state (Table 3), ${ }^{36}$ as also supported by the negative $\Delta \mu_{\mathrm{eg}}$ values computed for both compounds (Table 5).

It is worth noting that Pyr_TCF shows a higher (nearly double) molar absorption coefficient ( $\varepsilon$ ) compared to Anth_TCF in a variety of solvents, probably due to the extra conjugation

Table 3 Absorption maximum $\left(\lambda_{\max }\right)$ and molar absorption coefficient $(\varepsilon)$ for Anth_TCF and Pyr_TCF in different solvents

\begin{tabular}{|c|c|c|c|c|}
\hline \multirow[b]{2}{*}{ Solvent $\left(\varepsilon_{\mathrm{r}}\right)$} & \multicolumn{2}{|c|}{ Anth_TCF } & \multicolumn{2}{|l|}{ Pyr_TCF } \\
\hline & $\lambda_{\max } / \mathrm{nm}$ & $\varepsilon / \mathrm{cm}^{-1} \mathrm{M}^{-1}$ & $\lambda_{\max } / \mathrm{nm}$ & $\varepsilon / \mathrm{cm}^{-1} \mathrm{M}^{-1}$ \\
\hline $\mathrm{CHCl}_{3}(4.8)$ & 540 & 15200 & 533 & 26570 \\
\hline $\mathrm{PhCl}(5.6)$ & 535 & 16150 & 532 & 27140 \\
\hline $\mathrm{CH}_{2} \mathrm{Cl}_{2}$ (8.9) & 531 & 15840 & 532 & 24340 \\
\hline DMF (36.7) & 505 & 13900 & 511 & 24090 \\
\hline DMSO (46.7) & 507 & 14500 & 508 & 20850 \\
\hline
\end{tabular}

Table 4 EFISH $\mu \beta_{1.907}$ for Anth_TCF and Pyr_TCF in $\mathrm{CHCl}_{3}\left(5 \times 10^{-4} \mathrm{M}\right)$ and $\mathrm{CHCl}_{3}$ with addition of pyridine $\left(10^{-3} \mathrm{M} \text { solution }\right)^{a}$

\begin{tabular}{lll}
\hline & $\mu \beta_{1.907}$ & $\mu \beta_{1.907}$ \\
Compound & $\left(\times 10^{-48} \mathrm{esu}\right) \mathrm{CHCl}_{3}$ & $\left(\times 10^{-48} \mathrm{esu}\right) \mathrm{CHCl}_{3}+\mathrm{py}$ \\
\hline Anth_TCF & -85 & $\# \# \#$ \\
Pyr_TCF & -600 & -1700
\end{tabular}

${ }^{a}$ The uncertainty of the measurement is between \pm 5 and $\pm 10 \%$.

for Pyr_TCF. However, no significant difference has been observed in $\lambda_{\max }$ for both molecules, as shown in Table 3 and Fig. 5. We should note the extra shoulder observed for Pyr_TCF in neat chlorobenzene at $650 \mathrm{~nm}$. In this case, solubility issues have been found at the UV-Visible working concentration $\left(5 \times 10^{-5} \mathrm{M}\right)$ and for this solvent only, we could attribute this extra band to the formation of Pyr_TCF aggregates.

The investigated compounds display negative $\mu \beta_{1.907}$ EFISH responses and data are reported in Table 4 . The EFISH response is clearly sensitive to the local environment, as previously reported both theoretically ${ }^{37,38}$ and experimentally ${ }^{39}$ for push-pull polyenes.

The Oudar's “two-state” expression of hyperpolarisability states that:

$$
\beta \propto \frac{\mu_{\mathrm{eg}}^{2} \Delta \mu_{\mathrm{eg}}}{\Delta E_{\mathrm{eg}}^{2}}
$$

where $\mu_{\text {eg }}$ is the transition dipole moment, $\Delta \mu_{\text {eg }}$ the difference between the excited and the ground state dipole moments $\left(\mu_{\mathrm{e}}-\mu_{\mathrm{g}}\right)$ and $\Delta E_{\mathrm{eg}}$ the transition energy. A negative value of $\beta$ is therefore related to a ground state dipole moment higher than that of the excited state, as occurs in the case of push-pull polyenes for which the ground state shows a more significant charge separated character in comparison to the excited state. ${ }^{40}$

The EFISH experimental findings are therefore in perfect

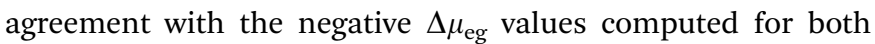
Ant_TCF and Pyr_TCF (Table 5) taking into account the contribution of the solvent (in this case, $\mathrm{CHCl}_{3}$ ) by means of the C-PCM method ( $\Delta \mu_{\mathrm{eg}}=-8.41$ and $-8.52 \mathrm{D}$, respectively) and they are supported by the negative solvatochromism of the NLO-phores.

In neat $\mathbf{C H C l}_{3}$ the $\mu \beta_{1.907}$ absolute value of $\mathbf{P y r} \_\mathbf{T C F}$ is $c a .7$ times higher than that of Anth_TCF.

The lower $\left|\mu \beta_{1.907}\right|$ value recorded for Anth_TCF could be ascribed to the non perfect planarity of the compound, as confirmed by the twist angle of 33.8 degrees between the anthracene donor and the TCF acceptor unit observed in the XRD experiments. This distortion from planarity also affects the molar absorption coefficients of the ICT absorption band responsible of the NLO response of the investigated chromophores, which is nearly twice higher for the pyrene derivative (Table 3 ). In accordance, the more planar $\pi$-conjugated architecture of Pyr_TCF (twist angle lower than 1 degree) produces higher $\mu \beta_{1.907}$ values, as predicted by both the "two-level" model $^{10,11}$ and by theoretical computations. The same behaviour was also evident in the case of 2-phenyl-benzoxazole derivatives, ${ }^{41}$ 
Table 5 DFT and TD-DFT parameters calculated at B3LYP/6-31(d) level of theory in different phases and solvents (via C-PCM)

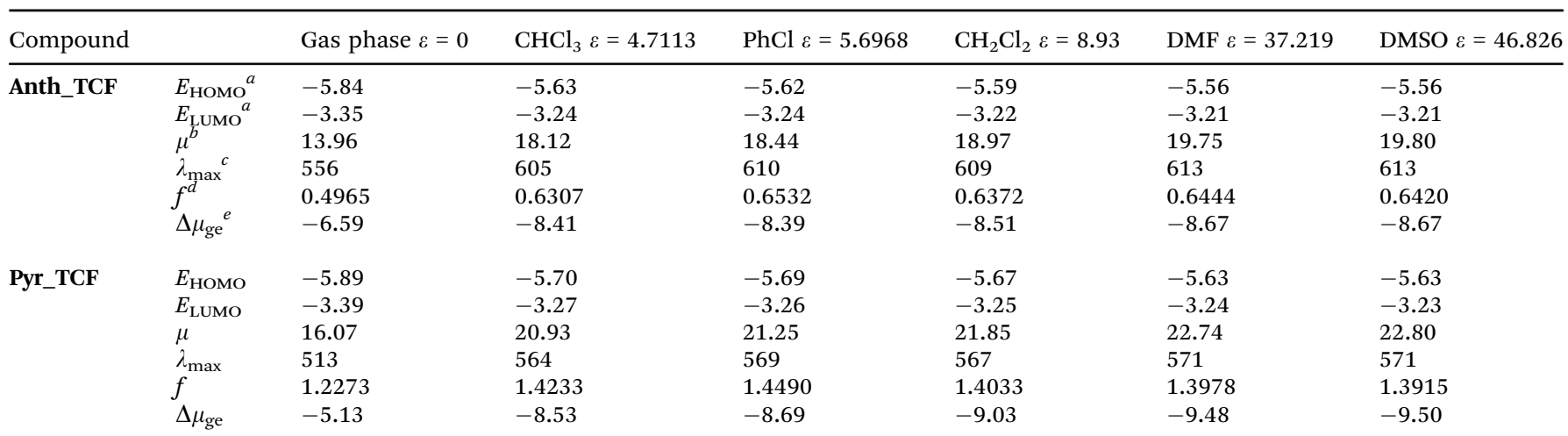

${ }^{a}$ Energy in eV vs. vacuum. ${ }^{b}$ Ground state dipole moment in Debye. ${ }^{c}$ First vertical electronic transition in nm. ${ }^{d}$ Oscillator strength. ${ }^{e}$ Calculated with the finite field approach and expressed in Debye.

push-pull benzimidazoles, ${ }^{42}$ zwitterionic merocyanines ${ }^{43}$ and push-pull spirobifluorene compounds. ${ }^{44}$

The well known tendency of pyrene and its derivatives to form aggregates by $\pi-\pi$ stacking of the aromatic rings ${ }^{45-47}$ and the recent report of a specific interaction between the pyrene fragment and the chlorinated hydrocarbon $\mathrm{CHCl}_{3}$, consisting of the formation of a complex with a charge transfer transition between the unoccupied halogen d-orbitals and the $\pi$-electron system of the aromatic component, ${ }^{38}$ prompted us to investigate the EFISH response of Pyr_TCF also in $\mathbf{C H C l}_{3}$ with addition of pyridine.

In this environment the $\left|\mu \beta_{1.907}\right|$ of Pyr_TCF is enhanced ca. three times in comparison to neat $\mathrm{CHCl}_{3}$. This latter evidence, combined with the higher solubility of Pyr_TCF in the presence of pyridine, seems to support the hypothesis that in pure $\mathrm{CHCl}_{3}$ solution Pyr_TCF is mainly in the form of an aggregate species (through the $\pi-\pi$ stacking of two contiguous chromophoric units favoured by the low polarity solvent), characterized by a lower second order NLO response. The addition of pyridine breaks the aggregation with a consistent enhancement of the $\left|\mu \beta_{1.907}\right|$ values. This aspect deserves further investigation, which is currently underway. Finally, it is worth noting that the $\mu \beta_{1.907}$ value of $-1700 \times 10^{-48}$ esu recorded for the Pyr_TCF derivative in $\mathrm{CHCl}_{3}$ with pyridine is remarkable for a NLO chromophore lacking a classical pushpull structure.

\section{Computational studies}

The electronic properties of TCF derivatives have been further investigated by DFT and TD-DFT calculations. The molecular structures were optimized using the X-ray structures as the starting point first in vacuum and then by taking into account the contribution of the solvent by means of the C-PCM method. There is good agreement between the calculated and experimental geometries, but particular attention should be focused on the torsion angle between the polycyclic aromatic moiety and TCF. In this case, the predicted torsion angles of approx. 42.5 and 0.1 degrees reproduce qualitatively the observed experimental values of 33.8 and 0.7 for Anth_TCF and Pyr_TCF, respectively. As can be seen in Fig. 6, the HOMO lies mainly on

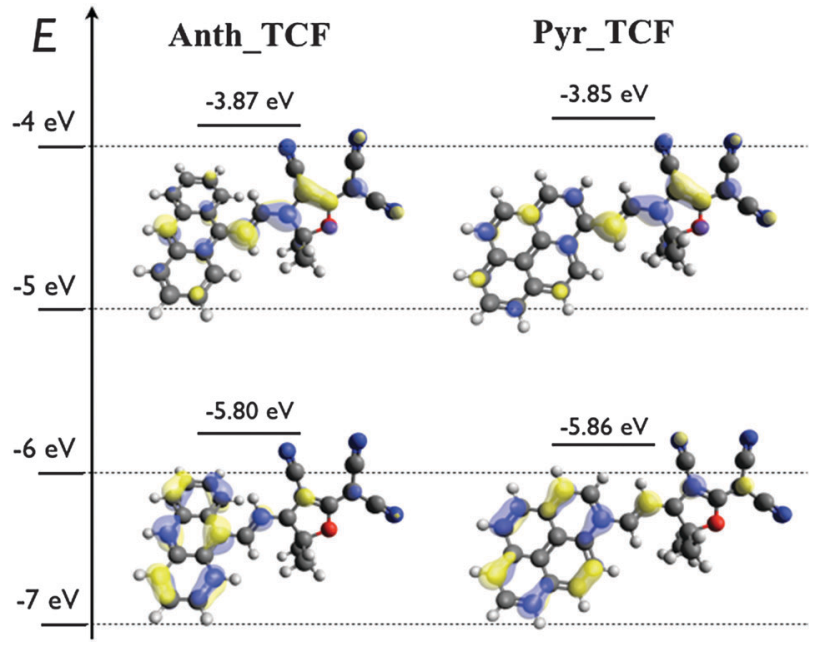

Fig. 6 Molecular orbital distribution of HOMO (bottom) and LUMO (top) of Anth_TCF and Pyr_TCF at B3LYP/6-31G(d) level of theory (isodensity = 0.04). Absolute HOMO and LUMO values are experimentally obtained from electrochemical means following the equation $E_{\text {HOMO/LUMO }}(\mathrm{eV})=$ $-4.88-E_{\text {OX/RED }}\left(V \text { vs. FC/FC }{ }^{+}\right)^{48}$

the polycyclic aromatic moiety whereas the LUMO is located on the electron-withdrawing TCF unit and ethylene bridge. The incorporation of the solvent via C-PCM has an important effect on the energy levels compared to gas phase, obtaining more accurate HOMO and LUMO energy levels in comparison with those experimentally derived from the electrochemistry. Furthermore, the increase of the ground-state polarity due to the solvent is also confirmed by enhancement of the calculated dipolar moments in solvents compared to those in the gas phase (Table 5).

TD-DFT calculations were performed in order to examine the electronic transition origins and characteristics and they are summarised in Table 5. In fact, vertical excitation energies showed that the first singlet excitation energy is responsible for the main absorption band. According to the distribution of the frontier orbitals (Table S1, ESI $\dagger$ ), it can be concluded that the HOMO to LUMO transition will be an ICT from the polycyclic aromatic moiety to the TCF unit. The $\lambda_{\max }$ for both chromophores were overestimated by $c a$. 60 and $40 \mathrm{~nm}$ for Anth_TCF 
and Pyr_TCF respectively, but the calculations qualitatively described the larger oscillator strength $(f)$ and therefore agree with the higher molar absorption obtained for the co-planar Pyr_TCF molecule.

TD-DFT calculations were also performed in different solvents with a gradual increment in simulated solvent electric fields $\left(\mathrm{CHCl}_{3}<\mathrm{PhCl}<\mathrm{CH}_{2} \mathrm{Cl}_{2}<\mathrm{DMF}<\mathrm{DMSO}\right)$ to investigate the effect of solvent polarity on the simulated absorption. In this case, the negative solvatochromic behaviour is well reproduced, where $\lambda_{\max }$ decreased upon an increment of solvent polarity. Finally, in order to find the difference between the excited and ground state dipole moments $\left(\Delta \mu_{\mathrm{eg}}\right)$ we performed TD-DFT calculations in the presence and absence of external electric field, where the molecular dipole and electric field are aligned to the $z$-axis. ${ }^{24} \Delta \mu_{\text {eg }}$ obtained were negative for all solvents, confirming the negative solvatochromic effect and the negative $\mu \beta_{\lambda}$ non-linear optical activity for both compounds.

\section{Conclusions}

New polycyclic aromatic hydrocarbons containing the TCF group have been synthesised and studied both experimentally and theoretically in order to elucidate the difference in nonlinear optical activity. Both compounds showed very similar absorption maxima, solvatochromic effect and electrochemical properties, however a 20-fold higher non-linear optical activity was found for Pyr_TCF. We attribute this huge difference to the higher molar absorption in DMF of Pyr_TCF $\left(24090 \mathrm{~cm}^{-1} \mathbf{M}^{-1}\right)$ compared to Anth_TCF (13900 $\mathrm{cm}^{-1} \mathbf{M}^{-1}$ ), likely arising from the large torsion angle between the polyaromatic unit and TCF obtained for the latter.

\section{Acknowledgements}

MP and NR thank the Engineering and Physical Sciences Research Council (EPSRC) APEX project for financial support. GSN thanks the University of Edinburgh for funding the diffractometer purchase.

\section{Notes and references}

1 P. N. Prasad and D. J. Williams, Introduction to nonlinear optical effects in molecules and polymers, Wiley, 1991.

2 J. Zyss, Molecular Nonlinear Optics: Materials, Physics and Devices, Academic Press Inc., 1994.

3 D. M. Burland, R. D. Miller and C. A. Walsh, Chem. Rev., 1994, 94, 31-75.

4 S. Barlow and S. R. Marder, Functional Organic Materials, Wiley-VCH Verlag GmbH \& Co. KGaA, 2007, pp. 393-437.

5 I. Ledoux and J. Zyss, C. R. Phys., 2002, 3, 407-427.

6 F. Tessore, E. Cariati, F. Cariati, D. Roberto, R. Ugo, P. Mussini, C. Zuccaccia and A. Macchioni, ChemPhysChem, 2010, 11, 495-507.

7 E. Cariati, M. Pizzotti, D. Roberto, F. Tessore and R. Ugo, Coord. Chem. Rev., 2006, 250, 1210-1233.
8 S. Di Bella, C. Dragonetti, M. Pizzotti, D. Roberto, F. Tessore and R. Ugo, in Molecular Organometallic Materials for Optics, ed. H. Bozec and V. Guerchais, Springer, Berlin Heidelberg, 2010, vol. 28, pp. 1-55.

9 H. Kang, A. Facchetti, H. Jiang, E. Cariati, S. Righetto, R. Ugo, C. Zuccaccia, A. Macchioni, C. L. Stern, Z. Liu, S.-T. Ho, E. C. Brown, M. A. Ratner and T. J. Marks, J. Am. Chem. Soc., 2007, 129, 3267-3286.

10 J. L. Oudar and D. S. Chemla, J. Chem. Phys., 1977, 66, 2664-2668.

11 J. L. Oudar, J. Chem. Phys., 1977, 67, 446-457.

12 C. Zhang, L. R. Dalton, M.-C. Oh, H. Zhang and W. H. Steier, Chem. Mater., 2001, 13, 3043-3050.

13 S. Liu, M. A. Haller, H. Ma, L. R. Dalton, S. H. Jang and A. K. Y. Jen, Adv. Mater., 2003, 15, 603-607.

14 Y.-J. Cheng, J. Luo, S. Huang, X. Zhou, Z. Shi, T.-D. Kim, D. H. Bale, S. Takahashi, A. Yick, B. M. Polishak, S.-H. Jang, L. R. Dalton, P. J. Reid, W. H. Steier and A. K. Y. Jen, Chem. Mater., 2008, 20, 5047-5054.

15 J. A. Davies, A. Elangovan, P. A. Sullivan, B. C. Olbricht, D. H. Bale, T. R. Ewy, C. M. Isborn, B. E. Eichinger, B. H. Robinson, P. J. Reid, X. Li and L. R. Dalton, J. Am. Chem. Soc., 2008, 130, 10565-10575.

16 R. Andreu, M. A. Cerdán, S. Franco, J. Garín, A. B. Marco, J. Orduna, D. Palomas, B. Villacampa, R. Alicante and M. Allain, Org. Lett., 2008, 10, 4963-4966.

17 M. Planells and N. Robertson, Eur. J. Org. Chem., 2012, 4947-4953.

18 M. Cossi, N. Rega, G. Scalmani and V. Barone, J. Comput. Chem., 2003, 24, 669-681.

19 M. J. Frisch, G. W. Trucks, H. B. Schlegel, G. E. Scuseria, M. A. Robb, J. R. Cheeseman, G. Scalmani, V. Barone, B. Mennucci, G. A. Petersson, H. Nakatsuji, M. Caricato, X. Li, H. P. Hratchian, A. F. Izmaylov, J. Bloino, G. Zheng, J. L. Sonnenberg, M. Hada, M. Ehara, K. Toyota, R. Fukuda, J. Hasegawa, M. Ishida, T. Nakajima, Y. Honda, O. Kitao, H. Nakai, T. Vreven, J. A. Montgomery, J. E. Peralta, F. Ogliaro, M. Bearpark, J. J. Heyd, E. Brothers, K. N. Kudin, V. N. Staroverov, R. Kobayashi, J. Normand, K. Raghavachari, A. Rendell, J. C. Burant, S. S. Iyengar, J. Tomasi, M. Cossi, N. Rega, J. M. Millam, M. Klene, J. E. Knox, J. B. Cross, V. Bakken, C. Adamo, J. Jaramillo, R. Gomperts, R. E. Stratmann, O. Yazyev, A. J. Austin, R. Cammi, C. Pomelli, J. W. Ochterski, R. L. Martin, K. Morokuma, V. G. Zakrzewski, G. A. Voth, P. Salvador, J. J. Dannenberg, S. Dapprich, A. D. Daniels, Farkas, J. B. Foresman, J. V. Ortiz, J. Cioslowski and D. J. Fox, Gaussian 09, Revision B.01, Wallingford, CT, 2009.

20 M. Hanwell, D. Curtis, D. Lonie, T. Vandermeersch, E. Zurek and G. Hutchison, J. Cheminf., 2012, 4, 17.

21 R. Bauernschmitt and R. Ahlrichs, Chem. Phys. Lett., 1996, 256, 454-464.

22 D. J. Tozer and N. C. Handy, J. Chem. Phys., 1998, 109, 10180-10189.

23 N. M. O'Boyle, A. L. Tenderholt and K. M. Langner, J. Comput. Chem., 2008, 29, 839-845. 
24 L. Pilia, M. Pizzotti, F. Tessore and N. Robertson, Inorg. Chem., 2014, 53, 4517-4526.

25 Agilent Technologies, CrysAlisPro, Agilent Technologies UK Ltd, Oxford, UK, 2011.

26 A. Altomare, G. Cascarano, C. Giacovazzo, A. Guagliardi, M. C. Burla, G. Polidori and M. Camalli, J. Appl. Crystallogr., 1994, 27, 435.

27 G. Sheldrick, Acta Crystallogr., Sect. A: Found. Crystallogr., 2008, 64, 112-122.

28 B. F. Levine and C. G. Bethea, Appl. Phys. Lett., 1974, 24, 445-447.

29 K. D. Singer and A. F. Garito, J. Chem. Phys., 1981, 75, 3572-3580.

30 I. Ledoux and J. Zyss, Chem. Phys., 1982, 73, 203-213.

31 A. Willetts, J. E. Rice, D. M. Burland and D. P. Shelton, J. Chem. Phys., 1992, 97, 7590-7599.

32 L. Beverina, J. Fu, A. Leclercq, E. Zojer, P. Pacher, S. Barlow, E. W. Van Stryland, D. J. Hagan, J.-L. Brédas and S. R. Marder, J. Am. Chem. Soc., 2005, 127, 7282-7283.

33 F. Würthner, S. Yao, T. Debaerdemaeker and R. Wortmann, J. Am. Chem. Soc., 2002, 124, 9431-9447.

34 F. Würthner and K. Meerholz, Chem. - Eur. J., 2010, 16, 9366-9373.

35 A. Marini, A. Muñoz-Losa, A. Biancardi and B. Mennucci, J. Phys. Chem. B, 2010, 114, 17128-17135.

36 S.-H. Kim, S.-Y. Lee, S.-Y. Gwon, Y.-A. Son and J.-S. Bae, Dyes Pigm., 2010, 84, 169-175.
37 A. Painelli, Chem. Phys., 1999, 245, 185-197.

38 R. Cammi, B. Mennucci and J. Tomasi, J. Am. Chem. Soc., 1998, 120, 8834-8847.

39 A. Abbotto, L. Beverina, S. Bradamante, A. Facchetti, C. Klein, G. A. Pagani, M. Redi-Abshiro and R. Wortmann, Chem. - Eur. J., 2003, 9, 1991-2007.

40 G. Bourhill, J.-L. Bredas, L.-T. Cheng, S. R. Marder, F. Meyers, J. W. Perry and B. G. Tiemann, J. Am. Chem. Soc., 1994, 116, 2619-2620.

41 A. Castaldo, R. Centore, A. Peluso, A. Sirigu and A. Tuzi, Struct. Chem., 2002, 13, 27-36.

42 A. Carella, R. Centore, A. Fort, A. Peluso, A. Sirigu and A. Tuzi, Eur. J. Org. Chem., 2004, 2620-2626.

43 A. J. Kay, A. D. Woolhouse, G. J. Gainsford, T. G. Haskell, T. H. Barnes, I. T. McKinnie and C. P. Wyss, J. Mater. Chem., 2001, 11, 996-1002.

44 F. Rizzo, M. Cavazzini, S. Righetto, F. De Angelis, S. Fantacci and S. Quici, Eur. J. Org. Chem., 2010, 4004-4016.

45 O. A. Khakhel, J. Appl. Spectrosc., 2001, 68, 280-286.

46 A. T. Haedler, H. Misslitz, C. Buehlmeyer, R. Q. Albuquerque, A. Köhler and H.-W. Schmidt, ChemPhysChem, 2013, 14, 1818-1829.

47 T. A. Sherstneva, K. P. Birin and V. V. Arslanov, Prot. Met. Phys. Chem. Surf., 2013, 49, 66-79.

48 M. Planells, L. Pelleja, J. N. Clifford, M. Pastore, F. De Angelis, N. Lopez, S. R. Marder and E. Palomares, Energy Environ. Sci., 2011, 4, 1820-1829. 